\title{
Menstrual Disorders in Adolescents: Review of Current Practice
}

\author{
Cara E. Williams Sarah M. Creighton \\ Department of Women's Health, University College London Hospital, London, UK
}

\section{Key Words}

Menorrhagia $\cdot$ Dysmenorrhoea $\cdot$ Irregular periods

\begin{abstract}
Menstrual disorders are common in adolescent girls. Periods can be irregular, heavy and/or painful, especially in the first few years following menarche. Serious pathology is rare; however, menstrual dysfunction can have a significant effect on daily activities and result in school absence. There are many treatment options which are safe to use in adolescents, although the evidence for their use is extrapolated from adult data. We present a clinical review of the current practice, including management of girls with other medical problems and learning difficulties.
\end{abstract}

Copyright $\odot 2012$ S. Karger AG, Basel

\section{Introduction}

Menstrual dysfunction is a common complaint amongst adolescent girls. An Australian cross-sectional study showed that approximately $25 \%$ of girls had significant menstrual dysfunction affecting life activities and resulting in school absence [1]. Menstrual cycles can be irregular and periods can be heavy (menorrhagia) and/or painful (dysmenorrhoea). Serious pathology is rare and menstrual cycles do improve with age. Symptoms can often be managed with reassurance and general advice such as appropriate use of simple analgesics. General practitioners are well placed to offer such care and referral to a specialist is usually not required.

However, in some situations input from a paediatrician or adolescent gynaecologist may be sought. Such situations would include cases where simple measures are unhelpful or where the girl has a complex medical condition which impacts upon either menstruation or treatment choices. In addition, girls with learning difficulties and their families may find even normal menstruation difficult to manage due to pain, fear or hygiene issues and may request intervention.

The purpose of this review is to:

- Describe the common features of adolescent menstrual dysfunction and what investigations to perform.

- Describe treatment options including risks and benefits.

- Focus on the management of menstrual difficulties in adolescents with learning difficulties.

There is scanty available guidance for clinicians managing this complex area of gynaecology and this

\section{KARGER}

Fax +4161306 1234

E-Mail karger@karger.ch

www.karger.com
(C) 2012 S. Karger AG, Basel

$1663-2818 / 12 / 0783-0135 \$ 38.00 / 0$

Accessible online at: www.karger.com/hrp
Cara Williams

Institute for Women's Health

University College London Hospital

250 Euston Road, London NW1 2PG (UK)

E-Mail Cara.williams@uclh.nhs.uk 
area of medicine is underresearched with very little robust evidence. The evidence available is often based on adult women, and it is assumed that it can be extrapolated to adolescents. The information presented in this review is based on clinical experience from a busy adolescent gynaecology service with close links to paediatrics supported by the medical literature where available.

\section{Adolescent Menstrual Dysfunction}

Due to the relative immaturity of the hypothalamicpituitary-ovary axis in the first 2 years following menarche, more than half of the menstrual cycles are anovulatory. This results in irregular cycles where cycle frequency can vary from less than 20 days to more than 90 days. After the first 1-2 years, the capacity for oestrogenpositive feedback on the anterior pituitary develops with the subsequent mid-cycle LH surge and ovulation, resulting in regulation of the menstrual cycle.

Anovulatory cycles are often heavy and prolonged with some girls bleeding for several weeks at a time. This can lead to iron deficiency anaemia, and in rare cases cardiovascular collapse requiring admission and blood transfusion. Initial anovulatory cycles tend to be painfree, although heavy menstrual loss can result in an element of dysmenorrhoea. When regular ovulatory cycles commence, the periods often become more painful due to the increased levels of circulating prostaglandins.

Although it is unusual to find a pathological cause for these symptoms, basic investigations are usually undertaken particularly in girls who fail to respond to first-line treatments. If the periods are heavy then a full blood count should be performed. Bleeding disorders are a relatively common cause of menorrhagia, occurring in 10$47 \%$ of cases [2]. Referral for haematological assessment should always be considered in cases of severe menorrhagia resistant to treatment.

Pelvic ultrasound is usually performed but is almost always normal. The transabdominal route should always be used in girls who have not been sexually active. The ovaries commonly have a multifollicular or polycystic appearance [3]. In cases of menorrhagia the endometrium may be thickened, although unlike adult women endometrial biopsy is not required for the investigation of menorrhagia in an adolescent. Congenital uterine arteriovenous malformations are a very rare cause of menorrhagia in adolescents, and can be diagnosed on Doppler ultrasound or MRI [4].
Rarely pelvic pain and dysmenorrhoea may be due to a genital tract anomaly and this is diagnosed by ultrasound. Endometriosis used to be regarded as a disease of adult women, but it is increasingly recognized that it can affect adolescent girls [5]. Studies have found it affects up to $70 \%$ of girls with chronic pelvic pain refractory to standard treatment [6]. Endometriosis is not always identified on ultrasound and if pain continues despite standard treatments, diagnostic laparoscopy should be performed.

\section{Treatment Options}

In most cases no underlying medical cause is identified. Despite this, symptoms can be extremely distressing and effective treatments are available. The choice of treatment depends on symptoms as well as the known potential side effects and risks of medication. Reassurance and advice about simple measures are crucial. However, many girls referred to tertiary care have already tried simple measures, and further intervention or treatment is often required. As for many medicines used in children, the majority of studies of efficacy have been performed on adult women and it is assumed these will apply equally to adolescent girls.

\section{Oral Progestogens}

Oral progestogens are widely used as first-line treatment for adolescent menstrual problems and can be taken continuously to defer or delay menstruation, or cyclically to improve irregular and heavy periods. There are currently only two preparations available in the UK norethisterone (NET) and medroxyprogesterone acetate (MPA, Provera). The mechanisms by which oral progestogens reduce blood loss are not well understood [7]. There are very few trials on the efficacy of oral progestogens used throughout the follicular and luteal phase; however, one small randomized controlled trial showed that NET reduced menstrual blood loss by $83 \%$ [8].

On occasions it may be necessary to defer or delay a menstrual period. Medical indications for this would include the need to avoid menstruation at the time of a complex planned surgical procedure or during a course of chemotherapy. Other requests may include avoiding menstruation at the time of public examinations or during a long planned family holiday. To defer menstrua- 
tion, either NET (5 $\mathrm{mg}$ b.d.) or MPA (10 $\mathrm{mg}$ t.d.s.) is started 5 days before the anticipated event and taken continuously on a daily basis for as long as required. Menstruation will occur 2-3 days after stopping the treatment. Menstruation can be deferred for a few days or weeks or several months depending on the indication for treatment.

Both NET and MPA are effective treatments for irregular menses and/or menorrhagia [8]. However, it is important they are taken for long enough each cycle. Whilst older treatment regimens recommended treatment just during the luteal phase (days 14-25), it is clear that treatment must be taken for 21 days each cycle with a once week break for menstruation [7, 9]. There have been no studies directly comparing NET and MPA and both are likely to be effective, although NET is most commonly used (5 $\mathrm{mg}$ b.d.). It is relatively androgenic and can therefore result in acne and hirsutism in some girls. Other side effects include mood disturbance, headache and breast tenderness.

Neither of these treatments are effective for dysmenorrhoea and analgesics may still be required during menstruation. In addition, neither are contraceptives and it is important that the girl is aware of this.

The main risk of treatment with oral progestogens is the potential risk of venous thromboembolism (VTE) and this is listed in the British National Formulary (BNF) [10]. There are certainly case reports of VTE associated with oral progestogens taken for dysfunctional uterine bleeding, although these are in older women, not adolescents $[11,12]$. However, there are no large studies. The only available studies are on progestogenonly pills (POPs), which have found no increased risk of VTE $[13,14]$, although POPs contain lower doses of progestogen (NET $350 \mu \mathrm{g}$ ). It is also important to remember that the background risk of VTE in young fit adolescent girls is extremely low. One study found the incidence of VTE in girls aged 15-19 years was $1.83 / 10,000$ woman years [13]. Any small increase in risk associated with oral progestogens would still result in a very low absolute risk of VTE. Current opinion is that any increased risk from oral progestogens is lower than the documented risk of combined oral contraceptive pills (COCPs) and in most cases the benefits outweigh the small potential risk.

The BNF (Paediatrics) states that oral progestogens are not licensed for use in children (age not specified); however, it also states that hormone therapy can be given at an appropriate age for the development of puberty [15].

Menstrual Disorders in Adolescents

\section{The POP}

The POP is also oral progestogen but in much smaller doses. It works by thickening cervical mucus to prevent sperm penetration, and in some cases it inhibits ovulation. Examples include Cerazette (desogestrel $75 \mu \mathrm{g}$ ), Micronor (NET $350 \mu \mathrm{g}$ ) and Norgeston (levonorgestrel 30 $\mu \mathrm{g})$. The POP is of little use in the management of adolescent menstrual dysfunction. Although it can lead to amennorhoea in some girls, it can also result in prolonged menses in up to $50 \%$ and breakthrough bleeding in $70 \%$ [16]. The reduction in menstrual flow and indeed the contraceptive benefit rely on accurate pill taking within a short time frame (within $3 \mathrm{~h}$ ). As compliance can be difficult for younger teenagers, the POP is usually unsuitable. Adolescents who require contraction are better off with the long-acting reversible contraceptives described later in this review.

POPs are licensed for use as a contraception. The BNF does not stipulate age limits, and the product literature for each individual preparation should be consulted for the licensing status prior to use [17].

\section{The COCP}

The COCP inhibits the production of $\mathrm{LH}$ and FSH from the anterior pituitary, leading to inhibition of ovulation. It is an effective first-line treatment for irregular menses, menorrhagia and dysmenorrhoea. A randomized controlled trial has found the COCP reduces menstrual blood loss by $43 \%$ [18]. It has also been found to reduce menstrual cramping by more than $50 \%$ [19]. If menstrual symptoms are particularly distressing affecting daily activities, the COCP can be tricycled or even taken continuously. This may be required prior to planned complex surgery, prior to chemotherapy or for public examinations and long holidays (as per oral progestogens).

The most commonly prescribed is Microgynon 30 (ethinyl estradiol $30 \mu \mathrm{g}$ with levonorgestrel $150 \mu \mathrm{g}$ ). Adolescent girls with acne or hirsutism due to polycystic ovarian syndrome would benefit with a more anti-androgenic pill containing a third-generation progestogen such as desogestrel (Marvelon) or gestodene (Femodene).

The COCP is an extremely effective form of contraception if taken correctly, and it also has several health benefits, including a reduction in the risk of ovarian [20], endometrial [21] and colorectal cancer [22].

Side effects include breast tenderness, mood disturbance and nausea and vomiting, but there is no evidence 
that the COCP is associated with weight gain [23]. The COCP will not affect final height, as menarche occurs after the growth spurt, and oestrogen levels at menarche will result in closure of the epiphyses. There may be parental concerns about the use of the contraceptive pill and its effect on sexual activity; however, there is no evidence that initiating treatment with the COCP brings forward the age of sexual debut.

The main risk with COCPs is VTE. As previously stated, the background risk of VTE in girls aged 15-19 years is very low (1.83/10,000 woman years [13]). A large European surveillance study has shown that the VTE risk increases 2-fold with COCP use [24]. This study did not show any difference in risk between the different progestogens. However, other studies have shown COCPs containing third-generation progestogens (desogestrel or gestodene) have a 2-fold increased risk of VTE compared with second-generation progestogens (NET or levonorgestrel) [25]. There is conflicting evidence about the VTE risk of drospirenone (Yasmin); however, the MHRA issued a statement saying the risk is higher than that of the second-generation progestogens, and it is likely to be similar to that of third-generation progestogens [26].

COCPs containing $20 \mu \mathrm{g}$ ethinyl estradiol were introduced in an attempt to reduce the risk of VTE associated with higher dose pills; however, they have a high incidence of irregular bleeding patterns [27] and therefore are not recommended in the management of adolescent menstrual dysfunction.

Girls with known thrombophilias (factor V Leiden deficiency, protein $\mathrm{C} / \mathrm{S}$ deficiency, prothrombin gene mutation, antithrombin III deficiency, antiphospholipid syndrome, systemic lupus erythematosus and myeloproliferative disorders) should not be prescribed the COCP [28]. Use of the COCP with factor V Leiden is known to increase the risk of VTE 35-fold [29].

A meta-analysis has shown that the COCP has a 2-fold increased risk of myocardial infarction and stroke [30], although a WHO Collaborative study did not show a significantly increased risk of haemorrhagic stroke in women $<35$ years [31]. Migraine with aura has been linked with a 2 -fold increased risk of ischaemic stroke, which is increased further by use of the COCP [32], and therefore the use of the COCP is contraindicated [28]. Hypertensive disease increases the risk of myocardial infarction and stroke in COCP users, but not the risk of VTE [33]. Systolic BP >160 mm Hg and diastolic BP > $95 \mathrm{~mm} \mathrm{Hg}$ are contraindications to the use of COCP [34]. BP should always be checked prior to commencing the COCP, after 3 months and then 6-monthly.
The risk of breast cancer in current users of the COCP is $24 \%$ above the baseline risk [35]. This risk reduces after stopping the COCP and returns to baseline risk after 10 years. The younger the age that the COCP is started, the greater the risk [35]; however, the baseline risk of breast cancer in adolescence is extremely low. A systematic review has shown that the COCP does not increase the disease risk in women with a family history of breast cancer [36], and therefore this is not a contraindication to use. However, if the girl is known to be a carrier of BRCA1/2, then the COCP is contraindicated [34].

Girls with epilepsy often notice an increase in seizure activity during periods, and effective treatment of menorrhagia can often improve control. Enzyme-inducing anti-epileptic drugs (phenytoin or carbamazepine) increase the metabolism of oestrogens and progestogens, reducing the contraceptive efficacy of the COCP. If the COCP is used for control of menstrual dysfunction and the girl is sexually active, condoms should always be advised. Lamotrigine levels are reduced by the COCP, which can result in increased seizure activity [37], and therefore COCP use is not advised in girls taking lamotrigine. NET can be used with all anti-epileptic drugs. Contraceptive efficacy of the long-acting reversible contraceptives is not affected by enzyme-inducing drugs [34], and therefore the levonorgestrel-releasing intra-uterine system (Mirena IUS) would be a more appropriate option in sexually active girls.

Bleeding disorders such as idiopathic thrombocytopenic purpura, Von Willebrand's disease, platelet dysfunction, haemophilia carriers and rare factor deficiencies can all be associated with heavy menstrual bleeding. All standard treatments including COCP can be used in bleeding disorders [28].

If the adolescent girl is not sexually active, the COCP can be started at any time during her cycle. If it is to be used as a contraception, it should be started at the onset of menstruation.

The COCP is licensed for use as a contraceptive and for menstrual symptoms in the BNF (age not stipulated). The product literature for each individual preparation should be consulted for the licensing status prior to use [38].

\section{Non-Hormonal Treatments}

\section{Tranexamic Acid}

Tranexamic acid is an antifibrinolytic which is effective at reducing menstrual loss by up to $50 \%[7,39,40]$. It 
is known to inhibit factors involved with blood clotting but does not have any effect on coagulation within health blood vessels. It does not therefore increase the risk of thrombosis [7, 41]. However, it is contraindicated in anyone with a personal or family history (first-degree relative) of thromboembolic disease [42]. It is initiated on the first day of menstruation ( $1 \mathrm{~g}$ t.d.s.) and stopped when the menstrual loss has normalized. It can lead to gastro-intestinal side effects with prolonged use. It can be used in girls with bleeding disorders [28]. Tranexamic acid is licensed for use in children over the age of 1 month [42].

\section{Mefenamic Acid}

Mefenamic acid is a non-steroidal anti-inflammatory drug which acts by inhibiting prostaglandin synthetase. It is effective for dysmenorrhoea, and can also help to reduce menstrual loss by up to $20 \%$ [40]. It is most effective if initiated the day prior to the start of menstruation and taken regularly during menses (500 $\mathrm{mg}$ t.d.s.). This can be difficult to predict in girls with irregular cycles. It is commonly prescribed in conjunction with tranexamic acid. It should be avoided or used with caution in girls with asthma or renal impairment. Side effects include nausea, diarrhoea and heartburn. Due to the association of non-steroidal anti-inflammatory drugs and gastric ulceration, mefenamic acid should be avoided in girls with bleeding disorders [7].

The Summary of Product Characteristics states that mefenamic acid is not recommended for children under 12 years. However, other non-steroidal anti-inflammatory drugs are licensed for use in children over 1 month [43].

\section{The Levonorgestrel Intra-Uterine System}

The levonorgestrel intra-uterine system (Mirena) is a long-acting reversible contraceptive. It is a T-shaped plastic frame with a rate-limiting membrane on the vertical stem which releases $20 \mu \mathrm{g}$ levonorgestrel into the uterine cavity each day. It prevents endometrial proliferation, thickens cervical mucus and in up to $25 \%$ inhibits ovulation [44]. It can be extremely useful in cases where firstline treatments have failed or when there are medical contra-indications to the use of the COCP. It can safely be used from menarche onwards $[45,46]$, and lasts for 5 years.

It is effective for menorrhagia and dysmenorrhoea. A systematic review showed that the Mirena significantly reduced menstrual blood loss by $74-97 \%$ [47]. It can cause irregular and heavy bleeding for the first 3-6 months; however, at 1 year 65\% have amenorrhoea or light bleeding [48]. It is an effective treatment for dysmenorrhoea and can be used in the management of endometriosis [49, 50].

In adolescents who have not been sexually active, the Mirena will need to inserted and removed under general anaesthesia. Potential risks of insertion include exacerbation of pelvic infection, uterine perforation and expulsion. Screening for sexually transmitted infections should be considered prior to insertion if a girl is at risk. Side effects include mood disturbance, acne and headache [46]. The Mirena does not increase the risk of VTE, it does not interact with any other drugs and there are no medical conditions in which the Mirena is contraindicated [46]. The levonorgestrel intra-uterine system is not licensed for use in girls under 18 years, although it is commonly used off-label in this age group without complications [51].

\section{Depo-Provera}

Depo-Provera is a depot injection of MPA given every 12 weeks. It is a long-acting reversible contraceptive which works primarily by inhibiting ovulation. It is effective for menorrhagia with up to $70 \%$ becoming amenorrhoeic by 12 months [52]. However, up to $50 \%$ of users will discontinue by 1 year usually due to bleeding problems (infrequent, spotting or prolonged bleeding) [52]. DepoProvera can be associated with increased weight gain, although this has only been shown to be significant in obese adolescents [53]. Depo-Provera has been shown to reduce bone mineral density in adolescents, and this reduction increases with duration of use [54]. The return of bone mineral density to baseline after discontinuation of Depo-Provera may not be adequate in adolescents as this is such a critical time for peak bone mass achievement; however, there is no long-term data for this $[52,53]$. It should therefore be used with caution in girls under 18 years, especially if there are other risk factors for osteoporosis such as corticosteroid use or immobility. If a girl chooses to use Depo-Provera having considered all other options, the risks and benefits of continuing treatment should be assessed after 2 years of use [52]. If Depo-Provera is used for a prolonged period of time, the addition of transdermal oestrogen as add-back to protect bones is advocated in a review by Zacharin [55]. However, this is not a licensed use, and there is no evidence base. DepoProvera does not increase the risk of VTE, myocardial infarction or stroke. Depo-Provera is licensed for girls over 12 years as a contraception, only after other options have been considered [56] (table 1). 
Table 1. Summary of treatment options

\begin{tabular}{|c|c|c|c|c|c|c|}
\hline & $\begin{array}{l}\text { Does it reduce } \\
\text { blood loss? }\end{array}$ & Can it reduce pain? & Can it regulate cycle? & $\begin{array}{l}\text { Does it } \\
\text { provide } \\
\text { contraceptive } \\
\text { cover? }\end{array}$ & Contraindications & License \\
\hline $\begin{array}{l}\text { Tranexamic } \\
\text { acid }\end{array}$ & $\begin{array}{l}\text { Yes, } 50 \% \\
\text { reduction in } \\
\text { blood loss }\end{array}$ & No & No & No & $\begin{array}{l}\text { Personal or family history of } \\
\text { thromboembolic disease }\end{array}$ & $\begin{array}{l}\text { Used in children } \\
>1 \text { month }\end{array}$ \\
\hline Mefenamic acid & $\begin{array}{l}\text { Yes, } 20 \% \\
\text { reduction in } \\
\text { blood loss }\end{array}$ & $\begin{array}{l}\text { Yes, anti- } \\
\text { inflammatory, } \\
\text { inhibits } \\
\text { prostaglandin } \\
\text { synthetase }\end{array}$ & No & No & $\begin{array}{l}\text { Caution in asthma and renal } \\
\text { impairment }\end{array}$ & $\begin{array}{l}\text { Age }>12 \text { years } \\
\text { (used off-label } \\
\text { in under } \\
12 \text {-year-olds) }\end{array}$ \\
\hline $\begin{array}{l}\text { Cyclical } \\
\text { progestogens }\end{array}$ & $\begin{array}{l}\text { Yes, } 80 \% \\
\text { reduction in } \\
\text { blood loss }\end{array}$ & No & Yes & No & $\begin{array}{l}\text { Liver tumours, genital/breast cancer, } \\
\text { severe arterial disease, acute } \\
\text { porphyria }\end{array}$ & $\begin{array}{l}\text { Age appropriate } \\
\text { to stage in } \\
\text { puberty }\end{array}$ \\
\hline POP & No & No & No & Yes & $\begin{array}{l}\text { Liver tumours, genital/breast cancer, } \\
\text { severe arterial disease, acute } \\
\text { porphyria }\end{array}$ & $\begin{array}{l}\text { Refer to } \\
\text { individual } \\
\text { preparation }\end{array}$ \\
\hline $\mathrm{COCP}$ & $\begin{array}{l}\text { Yes, }>40 \% \\
\text { reduction in } \\
\text { blood loss }\end{array}$ & $\begin{array}{l}\text { Yes, } 50 \% \text { reduction } \\
\text { in menstrual } \\
\text { cramping }\end{array}$ & Yes & Yes & $\begin{array}{l}\text { Previous thromboembolism or } \\
\text { multiple risk factors, migraine with } \\
\text { aura, } \mathrm{BP}>160 / 95 \mathrm{~mm} \mathrm{Hg} \\
\text { pulmonary hypertension, liver } \\
\text { disease/tumours, systemic lupus } \\
\text { erythematosus, acute porphyria, } \\
\text { gallstones, breast cancer, haemolytic } \\
\text { uraemic syndrome }\end{array}$ & $\begin{array}{l}\text { Refer to } \\
\text { individual } \\
\text { preparation }\end{array}$ \\
\hline Depo-Provera & $\begin{array}{l}\text { Yes, } 70 \% \\
\text { amenorrhoea by } \\
12 \text { months }\end{array}$ & $\begin{array}{l}\text { Yes, secondary to } \\
\text { amenorrhoea }\end{array}$ & $\begin{array}{l}\text { Yes, can cause } \\
\text { amenorrhoea, but 50\% } \\
\text { discontinuation due to } \\
\text { irregular bleeding }\end{array}$ & Yes & $\begin{array}{l}\text { Liver tumours, genital/breast cancer, } \\
\text { severe arterial disease, acute } \\
\text { porphyria }\end{array}$ & Age $>12$ years \\
\hline Mirena IUS & $\begin{array}{l}\text { Yes, } 65 \% \\
\text { amenorrhoea or } \\
\text { light bleeding by } \\
12 \text { months }\end{array}$ & $\begin{array}{l}\text { Yes, effective } \\
\text { treatment for } \\
\text { dysmenorrhoea and } \\
\text { endometriosis }\end{array}$ & $\begin{array}{l}\text { Yes, can cause } \\
\text { irregular bleeding for } \\
\text { first 3-6 months, then } \\
65 \% \text { amenorrhoea/ } \\
\text { light bleeding }\end{array}$ & Yes & $\begin{array}{l}\text { Breast cancer in last } 5 \text { years, } \\
\text { untreated sexually transmitted } \\
\text { infection or pelvic inflammatory } \\
\text { disease }\end{array}$ & $\begin{array}{l}\text { Age }>18 \text { years } \\
\text { (used off-label } \\
\text { in under } \\
\text { 18-year-olds) }\end{array}$ \\
\hline
\end{tabular}

\section{Adolescents with Learning Difficulties}

Normal and abnormal periods can be very difficult and distressing for girls with mental and/or physical handicap and their parents or carers. The girl might not understand why she is bleeding and may become distressed at seeing blood. There may be difficulties with hygiene especially if the periods are heavy, necessitating regular changes in sanitary protection or even clothing. This can be quite time-consuming for the parents/carers, especially if the girl is wheelchair-bound. Dysmenorrhoea can often be associated with nausea, vomiting and fainting, which the girl might find quite distressing. Premenstrual mood changes may be common, and might make the girl quite aggressive. It is understandable there- fore that the parents/carers are often very keen for the girls to achieve amenorrhoea or at least a predictable pattern of light bleeding that is more manageable.

A questionnaire-based study evaluating menstrual difficulties in adolescents with developmental disabilities showed that the severity of menstrual problems was similar to a normal population. Severe disability and carer dissatisfaction were highly predictive of seeking advice and treatment [57].

Girls with learning difficulties often have other medical problems associated with their underlying condition. These may be affected by their periods, for example girls with epilepsy may notice an increase in seizure activity. Some of the treatment options for menstrual dysfunction discussed above may also be contraindicated due to their 
other medical conditions for example the COCP in hypertensive disease.

Parents often have concerns about the risk of sexual abuse or coercion in these young girls who are extremely vulnerable. They may be keen for the girls to be on a reliable form of contraception to avoid pregnancy, which for some would be a devastating outcome. It may even lead to the parents requesting either sterilization or hysterectomy, which is discussed later. Conversely, some may have concerns about their daughter being on hormonal treatments especially contraceptives, and may prefer to try alternative treatment such as tranexamic acid and mefenamic acid.

Continuous NET and the COCP can both achieve amenorrhoea. There is very little data on the long-term continuous use of NET/COCP, although there is no evidence of any harm. Oral medication may not be suitable for some girls especially if there are associated feeding or swallowing difficulties. Girls who are confined to a wheelchair will have a higher thrombo-embolic risk and this should be considered prior to prescribing the COCP.

The Mirena IUS is an extremely effective treatment option in this group of girls, especially if they fail to respond to or cannot use first-line treatments. It has a high rate of amenorrhoea, and would also be an extremely effective form of contraception. It can be inserted and changed under general anaesthesia. The girl could continue to take NET or the COCP for a few months to allow time for the Mirena to work effectively.

\section{Surgical Options}

Sterilization is a permanent non-reversible form of contraception which is now very rarely used and should not be recommended in adolescents. Failure rate is 1:200 and risks include bleeding, infection, trauma to internal structures, conversion to laparotomy and even colosto- my, although these are all rare. Sterilization has no beneficial effect on the periods and has no role in the management of adolescent menstrual dysfunction.

If girls fail to respond to all of the standard treatment options, parents may request a hysterectomy as a last resort. This has enormous ethical and consent issues that need to be addressed. The girl is unlikely to be able to give informed consent, and the parents would be consenting on behalf of the young girl. Parental concerns and wishes may not be in the best interests of the young girl, which is ultimately the critical factor to assess prior to any decision making. If a hysterectomy is considered, the decision would need to be made within a multidisciplinary team following a thorough assessment of the girl's best interests.

\section{Conclusion}

Adolescent menstrual dysfunction is extremely common during the first few years following menarche. There are various treatment options available, all of which are safe to use in the adolescent period. The evidence of risk associated with the different treatments is extrapolated from adult data. As the baseline risk of serious pathology is lower in adolescents than adults, it has been assumed that the absolute risk associated with these treatments may actually be lower than the reported data, although there is little evidence to back this up. Other medical conditions should always be considered prior to initiating treatment, and recommendations from the UK medical eligibility criteria guidelines should be adhered to. Girls with learning difficulties can be a more complex group to treat, and may warrant a lower threshold for intervention.

\section{References}

-1 Parker M, Sneddon A, Arbon P: The menstrual disorder of teenagers (MDOT) study: determining typical menstrual patterns and menstrual disturbance in a large populationbased study of Australian teenagers. BJOG 2010;117:185-192.

$>2$ Boswell HB: The adolescent with menorrhagia: why, who and how to evaluate for a bleeding disorder. J Pediatr Adolesc Gynecol 2011;24:228-230.
-3 Venturoli S, Porcu E, Fabbri R, Pluccinetta V, Ruggeri S, Macrelli S, Paradisi R, Flamigni C: Longitudinal change of sonographic ovarian aspects and endocrine parameters in irregular cycles of adolescence. Paediatr Res 1995; 38:974-980.

4 Sanguin S, Lanta-Delmas S, Le Blanche A, Grardel-Chambenoit E, Merviel P, Gondry J, Fauvet R: Uterine arteriovenous malformations: diagnosis and treatment in 2011. Gynecol Obstet Fertil 2011;39:722-727.
75 Stavroulis AI, Saridogan E, Creighton SM, Cutner AS: Laparoscopic treatment of endometriosis in teenagers. Eur J Obstet Gynecol Reprod Biol 2006;125:248-250.

6 Laufer MR, Goitein L, Bush M, Cramer DW, Emans SJ: Prevalence of endometriosis in adolescent girls with chronic pelvic pain not responding to conventional therapy. J Pediatr Adolesc Gynecol 1997;10:199-202. 
7 National Institute for Health and Clinical Excellence: Heavy Menstrual Bleeding (NICE Clinical Guideline 44). 2007. http://www. nice.org.uk/nicemedia/live/11002/30401/ 30401.pdf.

8 Irvine GA, Campbell-Brown MB, Lumsden MA, Heikkilä A, Walker JJ, Cameron IT: Randomised comparative trial of the levonorgestrel intrauterine system and norethisterone for treatment of idiopathic menorrhagia. BJOG 1998; 105:592-598.

9 Lethaby A, Irvine G, Cameron I: Cyclical progestogens for heavy menstrual bleeding. Cochrane Database Syst Rev2008;CD001016.

10 British National Formulary 2012 6.4.1.2 Progestogens. http://www.medicinescomplete. com/mc/bnf/current/4336.htm\#_4336.2.

11 Rajput R, Dhuan J, Agarwal S, Gahlaut PS: Central venous sinus thrombosis in a young woman taking norethindrone acetate for dysfunctional uterine bleeding: case report and review of literature. J Obstet Gynaecol Can 2008;30:680-683.

-12 Lapecorella M, Orecchioni A, Dell'Orso L, Mariani G: Upper extremity deep vein thrombosis after suspension of progesterone-only oral treatment. Blood Coagul Fibrinolysis 2007;18:513-517.

-13 Lidegaard O, Lokkegaard E, Svendsen AL, Agger CA: Hormonal contraception and risk of venous thromboembolism: national follow-up study. BMJ 2009;339:b2890.

14 Cardiovascular disease and use of oral and injectable progestogen-only contraceptives and combined injectable contraceptives. Results of an international, multicenter, casecontrol study. World Health Organization Collaborative Study of Cardiovascular Disease and Steroid Hormone Contraception. Contraception 1998;57:315-324.

15 British National Formulary for Children 2011-2012, pp 377-379.

16 Kovacs G: Progestogen-only pills and bleeding disturbances. Hum Reprod 1996;11:2023.

17 British National Formulary for Children 2011-2012, pp 403-404.

-18 Fraser IS, McCarron G: Randomized trial of 2 hormonal and 2 prostaglandin-inhibiting agents in women with a complaint of menorrhagia. Aust NZ J Obstet Gynaecol 1991;31: 66-70.

19 Hendrix SL, Alexander NK: Primary dysmenorrhoea treatment with a desogestrelcontaining low-dose oral contraceptive. Contraception 2002;66:393-399.

20 Collaborative Group on Epidemiological Studies of Ovarian Cancer: Ovarian cancer and oral contraceptives: collaborative reanalysis of data from 45 epidemiological studies including 23,257 women with ovarian cancer and 87,303 controls. Lancet 2008; 371:303-314.

21 Jick SS, Walker AA, Jick H: Oral contraceptives and endometrial cancer. Obstet Gynecol 1993;82:931-935.
22 Fernandez E, La Vecchia C, Balducci A, Chatenoud L, Franceschi S, Negri E: Oral contraceptives and colorectal cancer risk: a meta-analysis. Br J Cancer 2001;84:722-727.

23 Gallo MF, Lopez LM, Grimes DA, Schulz KF, Helmerhorst FM: Combination contraceptives: effects on weight. Cochrane Database Syst Rev 2011;CD003987.

24 Dinger JC, Heinemann LAJ, Kuhl-Habichl D: The safety of drospirenone-containing oral contraceptive: final results from the European Active Surveillance study on oral contraceptives based on 142,475 womenyears of observation. Contraception 2007;75: 344-354.

25 Jick H, Kaye JA, Vasilakis-Scaramozza C, Jick SS: Risk of venous thromboembolism among users of third generation oral contraceptives compared with users of oral contraceptives with levonorgestrel before and after 1995: cohort and case-control analysis. BMJ 2000;321:1190-1195.

26 Medicines and Healthcare Products Regulatory Agency: Current Key Information on the Combined Oral Contraceptive, Yasmin - May 2011. Safety Warnings and Messages for Medicines. 2011. http://www.mhra.gov. uk/Safetyinformation/Safetywarningsalertsandrecalls/Safetywarningsandmessagesformedicines/CON117560.

27 Gallo MF, Nanda K, Grimes DA, Lopez LM, Schulz KF: $20 \mu \mathrm{g}$ versus $>20 \mu \mathrm{g}$ estrogen combined oral contraceptives for contraception. Cochrane Database Syst Rev 2011; CD003989.

28 Faculty of Sexual and Reproductive Healthcare: UK Medical Eligibility Criteria for Contraceptive Use. 2009. http://www.fsrh. org/pdfs/UKMEC2009.pdf.

29 Vandenbroucke JP, Koster T, Briet E, Reitsma PH, Bertina RM, Rosendaal FR: Increased risk of venous thrombosis in oral contraceptive users who are carriers of factor V Leiden mutation. Lancet 1994;344:14531457.

30 Baillargeon JP, McClish DK, Essah PA, Nestler JE: Association between the current use of low-dose oral contraceptives and cardiovascular arterial disease: a metaanalysis. J Clin Endocrinol Metab 2005;90: 3863-3870.

- 31 World Health Organization Collaborative Study of Cardiovascular Disease and Steroid Hormone Contraception: Haemorrhagic stroke, overall stroke risk, and combined oral contraceptives: results of an international, multicentre, case-control study. Lancet 1996;346:505-510.

32 Schurks M, Rist PM, Bigal ME, Buring JE, Lipton RB, Kurth T: Migraine and cardiovascular disease: systematic review and meta-analysis. BMJ 2009;339:b3914.

-33 Curtis KM, Mohllajee AP, Martins SL, Peterson HB: Combined oral contraceptive use among women with hypertension: a systematic review. Contraception 2006;73:179-188.
34 Faculty of Sexual and Reproductive Healthcare: Clinical Guideline. Combined Hormonal Contraception. October 2011. http:// www.fsrh.org/pdfs/CEUGuidanceCombinedHormonalContraception.pdf.

35 Collaborative Group on Hormonal Factors in Breast Cancer: Breast cancer and hormonal contraceptives: collaborative reanalysis of individual data on 53,297 women with breast cancer and 100,239 women without breast cancer from 54 epidemiological studies. Lancet 1996;347:1713-1727.

36 Gaffield ME, Culwell KR, Ravi A: Oral contraceptives and family history of breast cancer. Contraception 2009;80:372-380.

- 37 Sabers A, Buchholt JM, Uldall P, Hansen EL: Lamotrigine plasma levels reduced by oral contraceptives. Epilepsy Res 2001;47:151154

38 British National Formulary for Children 2011-2012, pp 396-402.

39 Lethaby A, Farquhar C, Cooke I: Antifibrinolytics for heavy menstrual bleeding. Cochrane Database Syst Rev 2009;CD000249.

40 Bonnar J, Sheppard BL: Treatment of menorrhagia during menstruation: randomised controlled trial of ethamsylate, mefenamic acid and tranexamic acid. BMJ 1996;313: 579-582.

41 Sundström A, Seaman H, Kieler H, Alfredsson L: The risk of venous thromboembolism associated with the use of tranexamic acid and other drugs used to treat menorrhagia: a case-control study using the General Practice Research Database. BJOG 2009;116:9197.

42 British National Formulary for Children 2011-2012, p 123.

43 http://www.medicines.org.uk/EMC/medicine/24513/SPC/Mefenamic+Acid+250mg+ Capsules/.

44 Nilsson CG, Lähteenmäki PLA, Luukkainen $\mathrm{T}$ : Ovarian function in amenorrheic and menstruating users of a levonorgestrel-releasing intrauterine device. Fertil Steril 1984; 41:52-55.

45 Faculty of Sexual and Reproductive Healthcare: Clinical Guideline. Contraceptive Choices for Young People. March 2010. http://www.fsrh.org/pdfs/ceuGuidanceYoungPeople2010.pdf.

46 National Institute for Health and Clinical Excellence (NICE): Long-acting reversible contraception: the effective and appropriate use of long-acting reversible contraception. 2005. http://www.nice.org.uk/pdf/CG030 fullguideline.pdf.

47 Stewart A, Cummins C, Gold L, et al: The effectiveness of the levonorgestrel-releasing intrauterine system in menorrhagia: a systematic review. BJOG 2001;108:74-86.

48 Crosignani PG, Vercellini P, Mosconi P, Oldani S, Cortesi I, De Giorgi O: A levonorgestrel-releasing intrauterine device versus hysteroscopic endometrial resection in the treatment of dysfunctional uterine bleeding. Obstet Gynecol 1997;90:257-263. 
49 Fedele L, Bianchi S, Zanconato G, Portuese A, Raffaelli R: Use of a levonorgestrel-releasing intrauterine device in the treatment of rectovaginal endometriosis. Fertil Steril 2001;75:485-488.

50 Vercellini P, Frontino G, De Giorgi O, Aimi G, Zaina B, Crosignani PG: Comparison of a levonorgestrel-releasing intrauterine device versus expectant management after conservative surgery for symptomatic endometriosis: a pilot study. Fertil Steril 2003;80:305309.
51 British National Formulary for Children 2011-2012, p 406.

52 Faculty of Sexual and Reproductive Healthcare: Clinical Guideline. Progestogen-Only Injectable Contraception. November 2008. http://www.fsrh.org/pdfs/CEUGuidance ProgestogenOnlyInjectables09.pdf.

53 Gordon CM, Pitts SAB: Approach to the Adolescent Requesting Contraception. J Clin Endocrinol Metab 2012;97:9-15.

54 Lara-Torre E, Edwards CP, Perlman S, Hertweck SP: Bone mineral density in adolescent females using depot medroxyprogesterone acetate. J Pediatr Adolesc Gynecol 2004;17: $17-21$.
55 Zacharin MR: Puberty, contraception and hormonal management for young people with disabilities. Clin Pediatr 2009;48:149155.

56 http://www.medicines.org.uk/EMC/medicine/11121/SPC/Depo-Provera+150mg+ $\mathrm{ml}+$ Injection/.

57 Zacharin M, Savasi I, Grover S: The impact of menstruation in adolescents with disabilities related to cerebral palsy. Arch Dis Child 2010;95:526-530. 